\title{
EVACUAÇÃO EMERGENCIAL EM LOCAL DE REUNIÃO DE PÚBLICO: AVALIAÇÃO DAS CONDIÇÕES DE ACESSIBILIDADE E SEGURANÇA EM ESTÁDIO DE FUTEBOL BRASILEIRO
}

\section{EMERGENCY EVACUATION AT A PUBLIC MEETING PLACE: EVALUATION OF ACCESSIBILITY AND SECURITY CONDITIONS AT BRAZILIAN FOOTBALL STADIUM}

\author{
Douglas de Castro Brombilla ${ }^{1}$, Me. \\ Isabela Fernandes Andrade ${ }^{2}$, Dra. \\ João Carlos Souza³, Dr.
}

(1) Instituto Federal de Educação, Ciência e Tecnologia do Rio Grande do Sul - Campus Rio Grande e-mail: douglas.brombilla@riogrande.ifrs.edu.br
(2) Universidade Federal de Pelotas e-mail: acessiarq@gmail.com

(3) Universidade Federal de Santa Catarina e-mail:joao.carlos@ufsc.br

Palavras-chave: acessibilidade, segurança, evacuação emergencial, estádio de futebol.

\begin{abstract}
Resumo: Estádios de futebol são edificações que costumam receber muitas pessoas em virtude da popularidade do esporte no Brasil. É elevado o número de estádios que necessitam de adaptações, principalmente aquelas relacionadas à inserção dos itens básicos de conforto e segurança para os espectadores, pois em função da grande concentração de público, são caracterizados como edifícios de alto risco de acidentes. Este trabalho tem como objetivo apresentar os resultados alcançados a partir da avaliação das condições de acessibilidade e segurança para a evacuação emergencial em um estádio de futebol brasileiro. O estudo se justifica em função dos grandes desastres ocorridos em locais de reunião de grande público e que poderiam ser minimizados se fossem previstas condições adequadas de segurança.
\end{abstract}

Key-words: accessibility, security, emergency evacuation, football stadium.

Abstract: Football stadiums are buildings that usually receive many people because of the popularity of the sport in Brazil. The number of stadiums that require adaptations is high, especially those related to the insertion of basic comfort and safety items for spectators, since, due to the great concentration of the public, they are characterized as buildings at high risk of accidents. This paper aims to present the results obtained from the evaluation of accessibility and safety conditions for emergency evacuation in a Brazilian soccer stadium. The study is justified by major disasters in large public places and could be minimized if adequate safety conditions were envisaged. 


\section{$16^{\circ}$ \\ ERGODESIGN USIHC CINAHPA}

$16^{\circ}$ Ergodesign - Congresso Internacional de Ergonomia e Usabilidade de Interfaces Humano Tecnológica: Produto, Informações Ambientes Construídos e Transporte

$16^{\circ}$ USIHC - Congresso Internacional de Ergonomia e Usabilidade de Interfaces Humano Computador

CINAHPA | 2017 - Congresso Internacional de Ambientes Hipermídia para Aprendizagem.

\section{Introdução}

Estádios de futebol são edificações que costumam receber muitas pessoas em virtude da popularidade do esporte no Brasil. Em 2014, o país foi sede da Copa do Mundo FIFA e, para tanto, alguns novos estádios foram construídos e outros passaram por modernização, muito embora a parcela de estádios modernizada e/ou construída para esse evento é pequena se considerada a quantidade existente no país. É elevado o número de estádios que necessitam de adaptações, principalmente aquelas relacionadas à inserção dos itens básicos de conforto e segurança para os espectadores.

O estudo justifica-se a partir dos desastres ocorridos em locais de reunião de grande público como é o caso dos estádios de futebol - em função de causas diversas, como brigas, incêndios, quedas de estrutura, atentados terroristas e catástrofes naturais e que poderiam ser minimizados se apresentassem condições adequadas para a evacuação. Portanto, este trabalho tem como objetivo avaliar as condições de acessibilidade e segurança para a evacuação emergencial em estádio de futebol brasileiro.

O objeto de estudo trata-se do Estádio Aderbal Ramos da Silva - conhecido como Estádio da Ressacada (Figura 1), localizado na cidade de Florianópolis, Brasil.

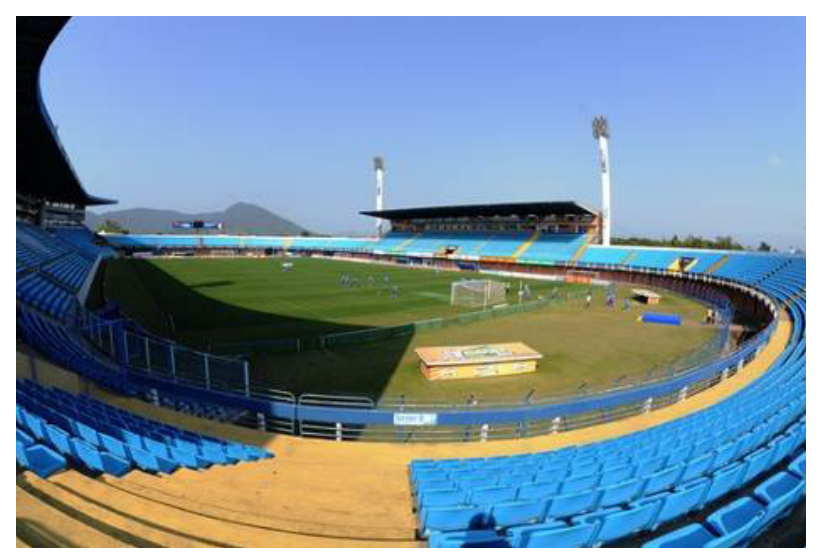

Figura 1 - Estádio da Ressacada. Fonte: Savio Hermano.
Este estádio pertence ao Avaí Futebol Clube e foi inaugurado em 1983. Atualmente apresenta capacidade de 17.800 espectadores, mas existe um projeto de ampliação para que o estádio atinja a capacidade de 35 mil espectadores, todos acomodados em cadeiras nos setores de arquibancada, camarotes e área VIP.

\section{Referencial Teórico}

O referencial teórico foi estruturado a partir de quatro tópicos principais: locais de reunião de público, segurança, acessibilidade e estádios de futebol.

\subsection{Locais de reunião de público}

A NBR 9050 (2015, p. 5) classifica locais de reunião como: "espaço interno ou externo que acomode grupo de pessoas reunidas para atividade de lazer, cultural, política, social, educacional, religiosa ou para consumo de alimentos e bebidas.".

São considerados locais de reunião de grande público: cinemas, teatros, estádios, igrejas, auditórios, salões de exposições, boates, clubes, circos, centro de convenções, restaurantes e congêneres.

Esses locais são ponderados de risco elevado em função da aglomeração de pessoas e, assim, sua evacuação deve ser tratada como elemento fundamental para salvaguardar a vida dos ocupantes do estabelecimento ou espaço aberto. Por isso, é importante um bom gerenciamento de risco e um bom plano de emergência e contingência.

A reunião de grande público não necessariamente acontece em ambientes fechados. Um exemplo que se tem no Brasil é o carnaval. Em cidades como Rio de Janeiro, Recife e Salvador, grupos gigantescos de foliões saem pelas ruas em blocos carnavalescos. Nas passarelas do samba, multidões estão nas arquibancadas assistindo ao desfile das escolas. 


\section{$16^{\circ}$ \\ ERGODESIGN USIHC CINAHPA}

Os estádios apresentam, ainda, uma particularidade: além de jogos de futebol, caracterizam-se como espaços utilizados para outros eventos, como shows e convenções, o que dificulta, muitas vezes, seu planejamento emergencial.

\subsection{Maiores desastres ocorridos no Brasil}

Dois dos maiores acidentes no Brasil que vitimaram centenas de pessoas em locais de grande concentração de público ocorreram em espaços de entretenimento.

O primeiro desastre e também considerado o maior já ocorrido no Brasil foi o incêndio no Gran Circo Norte-Americano (Figura 2) na cidade de Niterói, no estado do Rio de Janeiro, no dia dezessete de dezembro de 1961. O desastre, de classificação tecnológica, foi ocasionado por um ato de vandalismo organizado por ex-funcionários, que atearam fogo na lona do circo no momento em que ocorria um espetáculo com lotação máxima.

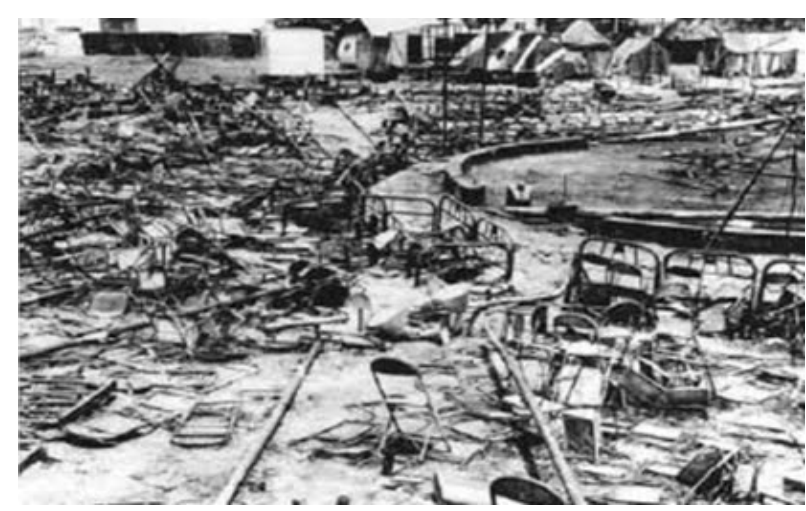

Figura 2 - Incêndio no Gran Circo Norte-Americano. Fonte: http://www.anosdourados.blog.br/2010/04/fatosnoticias-da-epoca.html.

O circo contava no momento do acidente com um público de, aproximadamente, três mil espectadores. As mortes ocorreram por queimaduras oriundas dos pingos de fogo que caíram da lona em chamas e por atropelamento, ao serem pisoteadas no momento da evacuação.

Ficou evidenciado, na época, que o fogo não foi o $16^{\circ}$ Ergodesign - Congresso Internacional de Ergonomia e Usabilidade de Interfaces Humano Tecnológica: Produto, Informações Ambientes Construídos e Transporte

$16^{\circ}$ USIHC - Congresso Internacional de Ergonomia e Usabilidade de Interfaces Humano Computador

CINAHPA | 2017 - Congresso Internacional de Ambientes Hipermídia para Aprendizagem.

principal fator das mortes, mas sim a falta de saídas suficientes e de pessoas treinadas para agirem em situações de emergência. Segundo Ventura (2011), o incêndio durou menos de dez minutos e foi suficiente para que centenas de espectadores fossem queimados, pisoteados ou morressem asfixiados. O resultado final do desastre foi de quinhentos e três pessoas mortas, dos quais $70 \%$ eram crianças.

O segundo maior desastre ocorrido no Brasil, também tecnológico, aconteceu na cidade de Santa Maria, no estado do Rio Grande do Sul, no dia 27 de janeiro de 2013. O fato se deu na boate chamada Kiss (Figura 3), que possuía, no momento do desastre, uma superlotação de, aproximadamente, mil e quinhentas pessoas. Segundo relato de testemunhas e também apurado pelas investigações, o desastre começou devido ao acionamento de um elemento pirotécnico no momento de um show.

Quatro fatores foram os principais causadores das mortes dos ocupantes do estabelecimento: asfixia por inalação de fumaça tóxica (oriunda do material de isolamento acústico), esmagamento e pisoteamento no momento da evacuação, falta de um plano de emergência, falta de pessoas treinadas e capacitadas no local e deficiências no projeto arquitetônico e de prevenção contra incêndio (PPCI), sendo que o local possuía apenas uma saída e não oferecia saída de emergência. $\mathrm{O}$ acidente vitimou 242 pessoas.

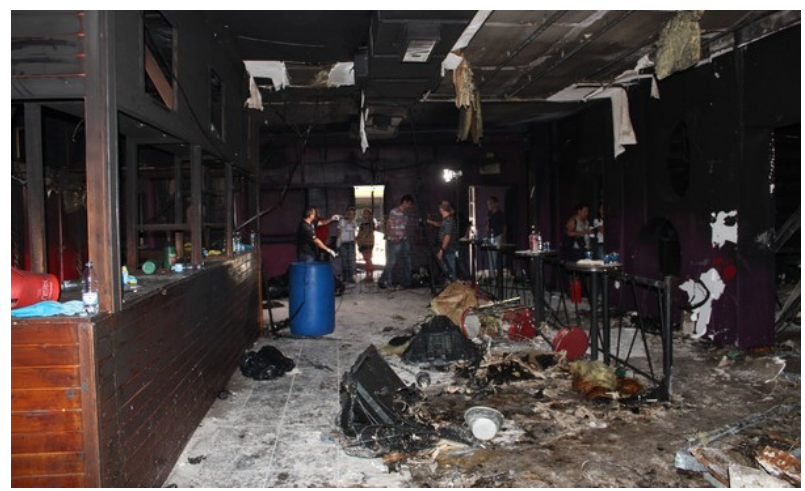

Figura 3 - Incêndio na Boate Kiss.

Fonte: Divulgação / Polícia Civil do RS. 
$16^{\circ}$ Ergodesign - Congresso Internacional de Ergonomia e Usabilidade de Interfaces Humano Tecnológica: Produto, Informações Ambientes Construídos e Transporte

$16^{\circ}$ USIHC - Congresso Internacional de Ergonomia e Usabilidade de Interfaces Humano Computador

Os exemplos citados demonstram que, mesmo com uma diferença de mais de cinquenta anos entre os acidentes e se tratando de lugares distintos, $o$ incêndio não foi o causador principal das mortes, mas a morte por esmagamento e asfixia. Tudo isso foi originado por falta de rotas definidas para uma eficiente evacuação, falta de um plano de emergência e número insuficiente de saídas.

Esse tipo de acidente pode ocorrer a qualquer momento e em qualquer local independente da natureza de seu uso. Por tudo isso, deve-se prevenir, minimizar e eliminar os riscos oriundos da edificação já na elaboração do projeto para auxiliar e facilitar a retirada dos ocupantes de forma rápida e segura.

\subsection{Segurança}

A palavra "segurança" significa a variável inversa do risco, e quanto maior o risco, menor é a segurança, e vice-versa. Portanto, aumentando-se a segurança, consegue-se reduzir o risco.

A violência é o principal motivo da diminuição do público nos estádios, e, no caso de emergência, é um potencial causador de tumultos. Isso demonstra que, além dos riscos de desastres nos locais de grande concentração de público, as autoridades estão preocupadas com o avanço da violência. Essa violência, muitas vezes, é provocada por pequenos grupos e pode desencadear eventos mais graves, em que seja necessário o abandono rápido do local.

\subsection{Acessibilidade}

As pessoas apresentam características diferentes entre si, seja em relação ao sexo, à idade ou à cultura. Em virtude disso, é necessário conhecer essas diferenças ao projetar espaços, levando-se em consideração todos esses aspectos.

Quando se tratam de locais de grande concentração de público, como no caso de estádios de futebol, encontram-se pessoas de diversas faixas etárias, estaturas, com algumas deficiências e, ainda, pessoas com mobilidade reduzida.
O que isso acarreta nos estádios ou em outros locais de reunião de grande público? Pode dificultar a evacuação do local e, por esse motivo, jaz a importância de relacionar esse estudo à acessibilidade.

$\mathrm{Na}$ Arquitetura, a acessibilidade não se restringe a espaços que possam ser utilizados por todas as pessoas de forma equivalente. Dischinger, Bins Ely e Piardi (2012) definem que "acessibilidade espacial significa bem mais do que poder atingir um lugar desejado. É também necessário que o local permita ao usuário compreender sua função, sua organização e relações espaciais, assim como participar das atividades que ali ocorrem.”. Essas ações devem ser realizadas com segurança, conforto e independência.

Além disso, para que um percurso seja acessível e seguro, é necessário que sejam trabalhadas as diversas formas de orientação espacial, bem como o conceito de rota acessível. A NBR 9050 (2015, p. 5) define rota acessível como "trajeto contínuo, desobstruído e sinalizado, que conecte os ambientes externos ou internos de espaços e edificações, e que possa ser utilizado de forma autônoma e segura por todas as pessoas, inclusive aquelas com deficiência e mobilidade reduzida.”.

\subsection{Estádios de futebol}

O futebol é um esporte muito difundido no Brasil e por, esse motivo, muitas vezes, os estádios são tratados como edifícios muito importantes. Esses elementos arquitetônicos assumem importância no contexto das cidades, até mesmo, como pontos turísticos e como referenciais de localização.

Em função da atualização de alguns conceitos e normas vigentes, muitos estádios antigos precisaram ser removidos para dar lugar à construção de novas edificações.

Exemplo disso aconteceu com o estádio de Wembley, em Londres, onde foi disputada a final da Copa do Mundo de 1966. No ano de 2003, o estádio foi demolido e, em seu terreno, foi construído um novo estádio com o mesmo nome, porém, atendendo todas as exigências atuais de 


\section{$16^{\circ}$ \\ ERGODESIGN USIHC CINAHPA}

$16^{\circ}$ Ergodesign - Congresso Internacional de Ergonomia e Usabilidade de Interfaces Humano Tecnológica: Produto, Informações Ambientes Construídos e Transporte

$16^{\circ}$ USIHC - Congresso Internacional de Ergonomia e Usabilidade de Interfaces Humano Computador

CINAHPA | 2017 - Congresso Internacional de Ambientes Hipermídia para Aprendizagem. conforto e segurança; hoje, ele é considerado um dos melhores do mundo.

No Brasil, as adaptações às novas normas de conforto e segurança, muitas vezes, tornam-se inviáveis, pois os estádios mais antigos eram projetados sem muitas preocupações com segurança e para terem apenas arquibancadas e não cadeiras, o que aumenta a capacidade dos estádios e dificulta a contagem precisa do número de torcedores.

Por fim, cabe salientar que os estádios de futebol brasileiros são instalações esportivas, cujas estruturas físicas foram dimensionadas para um contexto diferente e menos complexo, em termos de necessidade de segurança, daquele encontrado atualmente nos eventos esportivos que sediam jogos importantes.

\section{Metodologia}

A metodologia envolveu a realização de visitas exploratórias e de entrevistas semiestruturadas.

Durante as visitas exploratórias registraram-se, em planilhas, dados referentes às condições de acessibilidade, segurança e rotas de fuga do estádio de futebol.

As planilhas adotadas para a avaliação das condições de acessibilidade foram desenvolvidas por Dischinger, Bins Ely e Piardi (2012) e referemse às circulações horizontais, circulações verticais e aos locais para atividades coletivas.

Dischinger, Bins Ely e Piardi (2012) desenvolveram seis planilhas que abordam os seguintes itens: área de acesso ao edifício, saguões, salas de recepção e espera, circulações horizontais, circulações verticais, sanitários para deficientes físicos e locais para atividades coletivas. Porém, para fins deste trabalho, foram utilizadas somente três.

A partir do quadro 1 pode-se verificar que as planilhas utilizadas para avaliar as condições de acessibilidade são estruturadas em nove colunas e estão divididas em seis itens: número identificador, legislação a que se refere, componentes de acessibilidade, itens a conferir, resposta e observações.

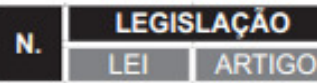

3.1 3.2

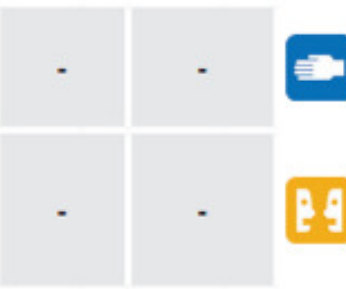

\section{c}

\section{ITENS A}

CONFERIR

MECANISMOS DE CONTROLE DE ACESSO

(se houver)

Quando o acesso às circulaçōes horizontais é

feito através de videofones e/ou interfones a botoeira é acessivel aos cadeirantes e às pessoas com baixa estatura?

Quando o acesso às circulações horizontais é feito através de videofones e/ou interfones, existe algum tipo de tecnologia assistiva para comunicação do surdo e/ou mudo para acesso ao edificio?

Quadro 1 - Exemplo da planilha aplicada no método de visita exploratória (acessibilidade). Fonte: Dischinger, Bins Ely e Piardi (2012).

Já a planilha adotada para avaliar as condições de segurança (quadro 2) foi desenvolvida por Brombilla (2014) e está estruturada em dez colunas e dividida em quatro conjuntos: legislação, itens a conferir, respostas e observações.
A construção da planilha abordou diversos instrumentos que cercam o tema. A finalidade da criação desse instrumento foi realizar o cruzamento das normas nacionais e a lei do Estatuto do Torcedor, com a norma internacional NFPA $101 \mathrm{e}$ as normas específicas da FIFA (Quadro 2). 


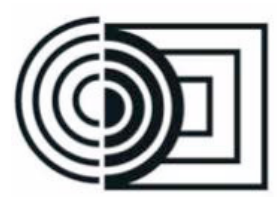

$16^{\circ}$ Ergodesign - Congresso Internacional de Ergonomia e Usabilidade de Interfaces Humano Tecnológica: Produto, Informações Ambientes Construídos e Transporte

$16^{\circ}$ USIHC - Congresso Internacional de Ergonomia e Usabilidade de Interfaces Humano Computador

CINAHPA | 2017 - Congresso Internacional de Ambientes Hipermídia para Aprendizagem.

\begin{tabular}{|c|c|c|c|c|c|c|c|c|c|}
\hline & & & & & \multicolumn{5}{|c|}{ PLANILHA DE AVALIAÇÃO DAS NORMAS DE SEGURANÇA } \\
\hline & & & & & Edifício: & ocal: & & Data: & Planilha: \\
\hline \multicolumn{10}{|c|}{ Legislação } \\
\hline \begin{tabular}{|l|} 
Norma \\
Nacional
\end{tabular} & Artigo & \begin{tabular}{c|c|} 
Norma \\
Internacional
\end{tabular} & Artigo & FIFA & Itens a conferir & & \begin{tabular}{|l|} 
Respostas \\
Sim Näo \\
\end{tabular} & 5 & observaçöes \\
\hline \multicolumn{10}{|c|}{ SAIDAS } \\
\hline NR-23 & 23.2 .1 & NFPA 101 & 7.2 .12 .2 .3 & 23 & A largura minima das aberturas de & saida é de $1,20 \mathrm{~m}$ ? & & & \\
\hline NR-23 & 23.2 .2 & NFPA 101 & 7.2 .1 & 5EEd. 2.2 & O sentido da abertura da porta é & para o exterior? & & & \\
\hline
\end{tabular}

Quadro 2 - Exemplo da planilha aplicada no método de visita exploratória (segurança).

Fonte: Brombilla (2014).

A planilha está estruturada em dez colunas e estão divididas em quatro conjuntos: legislação, itens a conferir, respostas e observações.

O conjunto da legislação foi subdividido em cinco colunas relacionadas às normas nacionais, internacionais e da FIFA. Na sexta coluna, são abordados os itens das normas, os quais se devem conferir. As colunas sete, oito e nove são destinadas às respostas encontradas nas verificações e, na última coluna, as observações pertinentes ao item abordado.

O registro da identificação das rotas de fuga foi ilustrado em pranchas (figura 4) também desenvolvidas por Brombilla (2014).

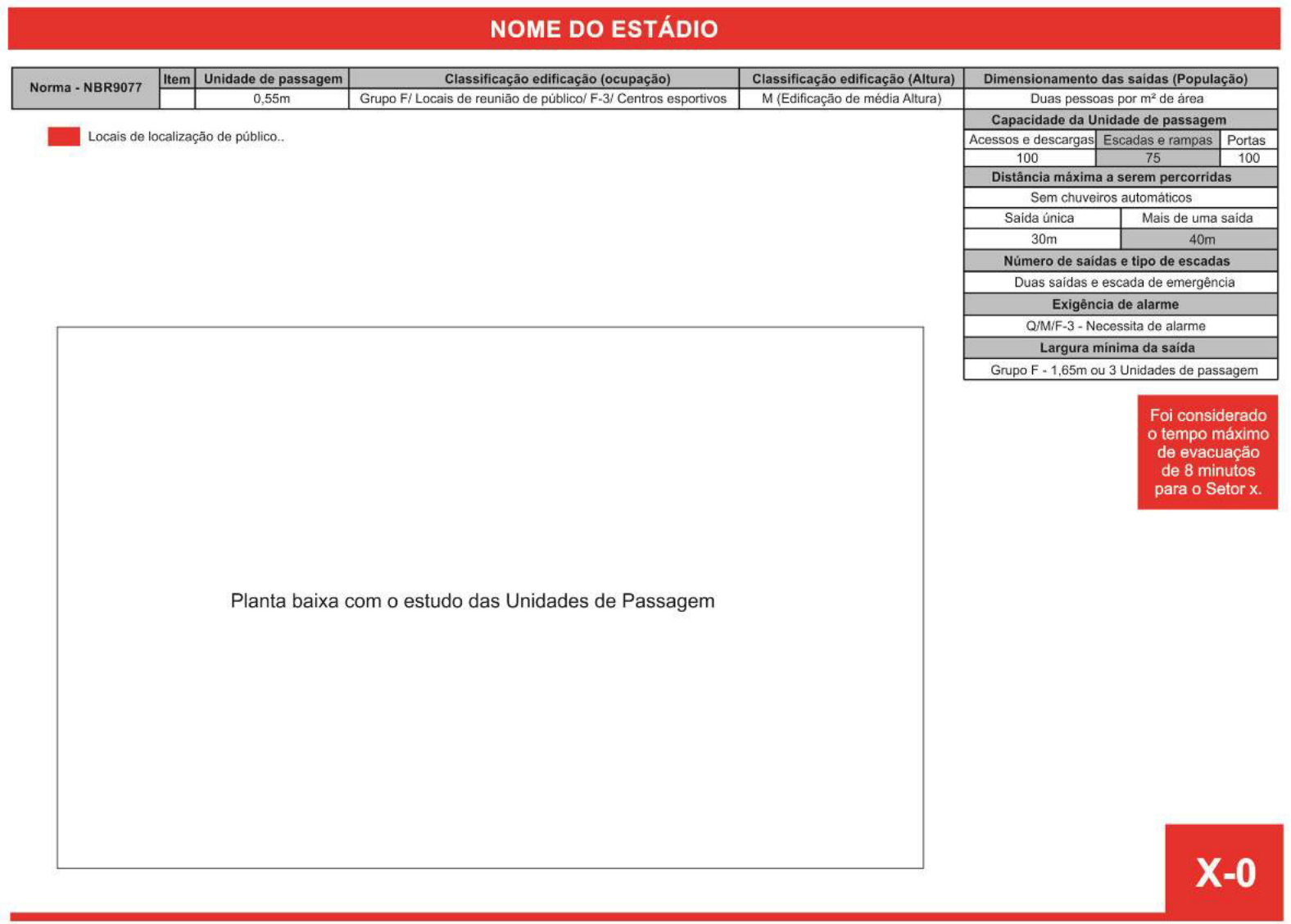

Figura 4 - Prancha de avaliação das rotas de fuga.

Realização:

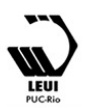




\section{$16^{\circ}$ \\ ERGODESIGN USIHC CINAHPA}

$16^{\circ}$ Ergodesign - Congresso Internacional de Ergonomia e Usabilidade de Interfaces Humano Tecnológica: Produto, Informações Ambientes Construídos e Transporte

$16^{\circ}$ USIHC - Congresso Internacional de Ergonomia e Usabilidade de Interfaces Humano Computador

CINAHPA | 2017 - Congresso Internacional de Ambientes Hipermídia para Aprendizagem.
Com posse dos dados e das plantas arquitetônicas, foi possível avaliar se o dimensionamento das rotas de fuga atendia a demanda de espectadores no que se referem à largura das circulações (unidade de passagem - U.P.), distâncias a serem percorridas e o deslocamento seguro do espectador até chegar a uma área segura, seja um refúgio ou a área externa do estádio.

Para facilitar o trabalho e o entendimento de toda a avaliação, optou-se por avaliar o estádio por setor, sendo que cada setor foi avaliado, em média, por três pranchas.

Por fim, as entrevistas semiestruturadas foram realizadas de forma aleatória, com cem espectadores, na entrada do estádio, sendo seu objetivo principal testar os conhecimentos dos espectadores em relação ao estádio e avaliar o seu comportamento em uma situação de tumulto generalizado. $\mathrm{O}$ formulário da entrevista se constitui de seis perguntas, sendo cinco fechadas e uma aberta.

Os respondentes foram questionados sobre os seguintes aspectos: se identificavam as saídas de emergência; se já foram orientados sobre procedimentos de evacuação em estádios; se estão preparados para enfrentar uma situação de tumulto; se já enfrentaram situações semelhante; e qual seria o comportamento numa situação de tumulto generalizado.

\section{Resultados}

Com a aplicação das planilhas durante as três visitas exploratórias, constatou-se que as rotas de fuga do estádio apresentam problemas nas circulações, tais como: barreiras físicas (figura 4), longa distância a ser percorrida pelos espectadores, não cumprimento do número mínimo de saídas, pontos de gargalos (afunilamento) e, em alguns casos, desrespeito a largura mínima exigida por norma para as circulações.

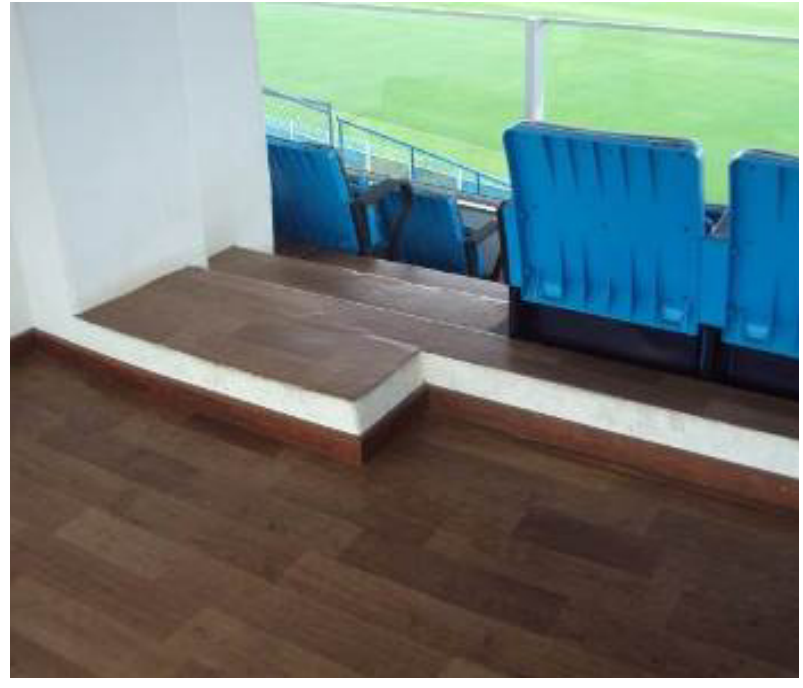

Figura 4 - Barreiras físicas configuradas a partir de desníveis na área de circulação.

Em relação à acessibilidade, identificaram-se problemas em itens básicos como corrimão instalado somente em uma altura (figura 5) embora a norma brasileira de acessibilidade (NBR9050, 2015) preveja a instalação em duas alturas diferentes.

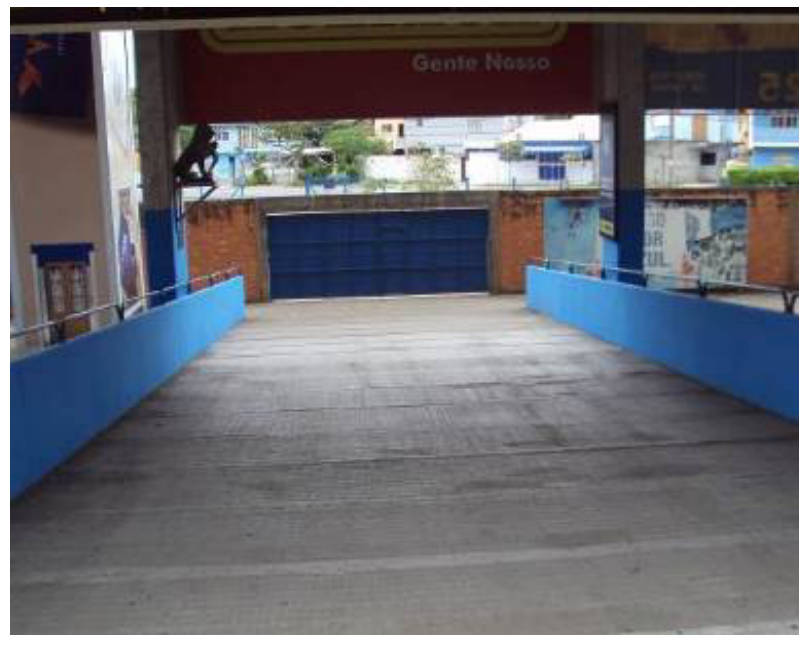

Figura 5 - ausência de corrimão em diferentes alturas junto à rampa.

Além disso, não há pisos táteis de alerta instalados no início e no término de escadas/rampas (figura $6)$. 

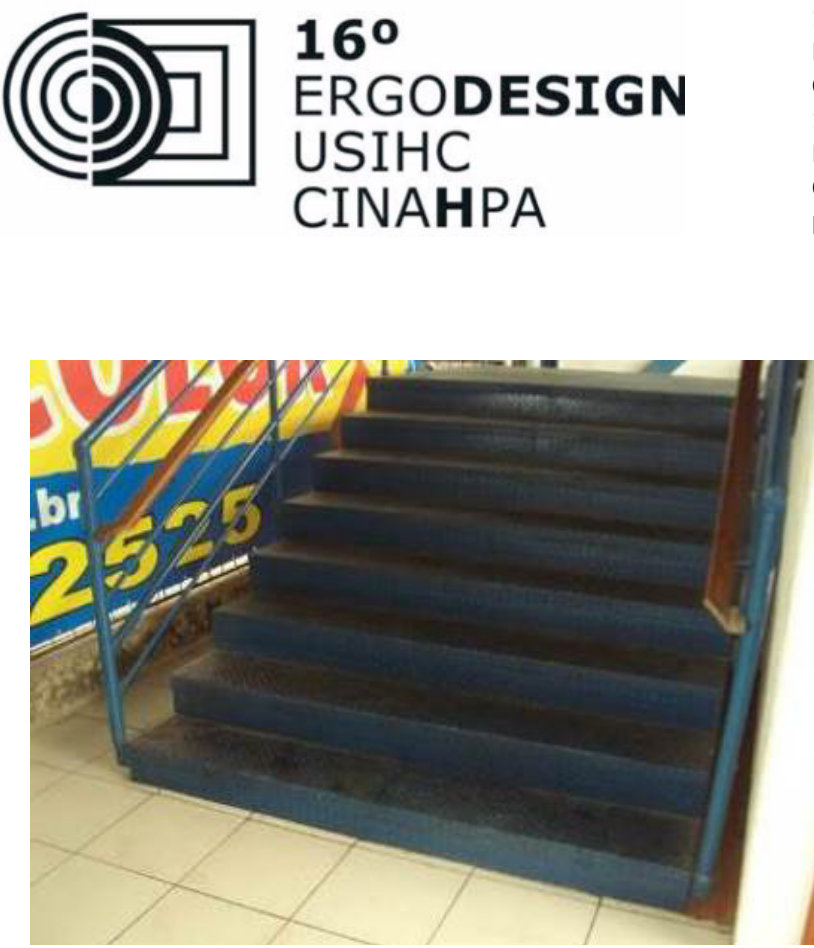

Figura 6 - ausência de piso tátil instalado no começo e no término da escada interna.

Referente à acessibilidade, o estádio da Ressacada possui dois setores que permitem o acesso e destinam um local para pessoas em cadeira de rodas (figura 7). Ambos os setores possuem elevadores para acesso das pessoas em cadeira de rodas, mas, em situação de emergência, não existe um refúgio para que essas pessoas aguardem a sua remoção.

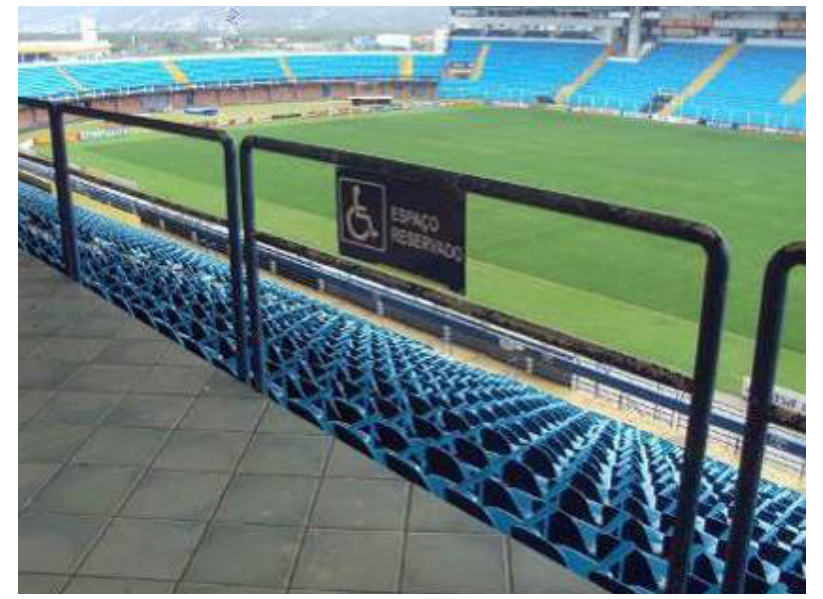

Figura 7 - Local destinada para a permanência de pessoas com deficiências não contempla assentos para obesos.

O estádio não possui saídas de emergência adicionais e, portanto, os mesmos acessos e circulações utilizados na entrada e saída de espectadores em situações normais são também utilizados em situação de emergência. $16^{\circ}$ Ergodesign - Congresso Internacional de Ergonomia e Usabilidade de Interfaces Humano Tecnológica: Produto, Informações Ambientes Construídos e Transporte

$16^{\circ}$ USIHC - Congresso Internacional de Ergonomia e Usabilidade de Interfaces Humano Computador

CINAHPA | 2017 - Congresso Internacional de Ambientes Hipermídia para Aprendizagem.
Através das entrevistas, constatou-se que as pessoas não identificam as saídas no estádio e não se sentem seguras em seu deslocamento em direção às saídas da edificação.

\section{Conclusões}

A metodologia utilizada no estudo foi facilitadora para que o objetivo proposto fosse atingido, visto que oportunizou conhecer a real situação do estádio, a legislação vigente, a opinião dos espectadores no ambiente de jogo, bem como a realização de análise crítica embasada na literatura acerca do tema.

O estádio avaliado - e por extensão os estádios brasileiros - precisam melhorar muito no quesito segurança. Através das visitas exploratórias, foi possível de constatar problemas de gestão de crises, falta de equipamentos de segurança e, mais importante, falta de pessoas treinadas e capacitadas para auxiliar em uma condição emergencial.

As rotas de fuga apresentam problemas nas circulações, que não mantêm larguras uniformes e, em alguns casos, não respeitam a largura mínima exigida por norma e, ainda, apresentam obstáculos que podem gerar lesão nos espectadores em situações de tumulto.

Com referência à acessibilidade, o estádio estudado apresenta problemas de instalação de equipamentos básicos, como corrimãos, pisos táteis de alerta no início e no fim de escadas e rampas, além de rampas com inclinação em desconformidade com a norma. Os espaços destinados a pessoas em cadeira de rodas estão limitados a alguns setores e não existem assentos para pessoas obesas, por exemplo.

O estádio não está preparado para que seja realizada a evacuação de pessoas com deficiência, pois não possui um plano para a sua retirada e não existe um local destinado para que a pessoa em cadeira de rodas aguarde sua remoção.

A ferramenta desenvolvida através das informações contidas nas normas de segurança foi um ponto a se destacar, pois possibilitou uma 


\section{$16^{\circ}$ \\ ERGODESIGN USIHC CINAHPA}

$16^{\circ}$ Ergodesign - Congresso Internacional de Ergonomia e Usabilidade de Interfaces Humano Tecnológica: Produto, Informações Ambientes Construídos e Transporte

$16^{\circ}$ USIHC - Congresso Internacional de Ergonomia e Usabilidade de Interfaces Humano Computador

CINAHPA | 2017 - Congresso Internacional de Ambientes Hipermídia para Aprendizagem. avaliação rápida através do cruzamento das normas nacionais com as internacionais.

Através das entrevistas, foi possível concluir alguns aspectos significativos para o estudo. As pessoas que não localizam as saídas no estádio e não se sentem seguras para se deslocar até elas ficaram em dúvida se existem saídas de emergência no local. Essa dúvida acontece pela falta de orientação aos espectadores.

Conforme as entrevistas, quando questionados se estão preparados para enfrentar uma situação de emergência, muitos indivíduos ainda tem uma série de dúvidas nas atitudes a serem tomadas. Essa insegurança vem ao encontro de como esse tema é tratado no Brasil, pois não se tem a cultura de orientação e treinamento de segurança para enfrentar situações adversas, enquanto em outros países isso é encarado como prioridade desde a educação básica.

\section{BIBLIOGRAFIA}

ABNT NBR 9050. Acessibilidade a edificações, mobiliário, espaços e equipamentos urbanos. Rio de Janeiro: ABNT, 2015. 148p.

BROMBILLA, Douglas de Castro. Evacuação emergencial em locais de reunião de público: caso de estádios de futebol brasileiros.

Dissertação de Mestrado apresentada ao Programa de Pós-Graduação em Arquitetura e Urbanismo da Universidade Federal de Santa Catarina. Disponível em: http://tede.ufsc.br/teses/ PARQ0195-D.pdf. Acesso em 17/11/2016.
CARDELLA, Benedito. Segurança no trabalho e prevenção de acidentes: uma abordagem holística: segurança integrada à missão organizacional com produtividade, qualidade, prevenção ambiental e desenvolvimento de pessoas. $1^{\text {a }}$ ed. - São Paulo: Atlas, 2012.

DISCHINGER, Marta; BINS ELY, Vera Helena Moro; PIARDI, Sonia Maria Demeda Groisman. Promovendo a Acessibilidade nos Edifícios Públicos: Programa de Acessibilidade às Pessoas com Deficiência ou Mobilidade Reduzida nas Edificações de Uso Público. Florianópolis: Ministério Público de Santa Catarina, 2012.

ENSSLIN, Leonardo; ENSSLIN Sandra R.; PACHECO, Giovanni C. Um estudo sobre segurança em estádios de futebol baseado na análise bibliométrica da literatura internacional. Revista Perspectivas em Ciência da Informação. v.17, n.2, p.71-91. 2012.

SANTA CATARINA (Estado). Corpo de Bombeiros. Norma de Segurança Contra Incêndio do Estado de Santa Catarina. Florianópolis, 1994.

VENTURA, Mauro. O espetáculo mais triste da Terra: o incêndio do Gran Circo NorteAmericano. São Paulo: Companhia das Letras, 2011. 